\title{
Article
}

\section{Preparation, structured delfberate practice and decision making in elite level football: The case study of Gary Neville (Manchester United FC and England)}

Horrocks, DE, McKenna, J, Whithead, AE, Taylor, PJ, Morley, AM and Lawrence, I

Available at http://clok.uclan.ac.uk/15815/

Horrocks, DE, McKenna, J, Whithead, AE, Taylor, PJ ORCID: 0000-0002-99998397, Morley, AM ORCID: 0000-0003-1942-1983 and Lawrence, I (2016) Preparation, structured deliberate practice and decision making in elite level football: The case study of Gary Neville (Manchester United FC and England). International Journal of Sports Science \& Coaching, 11 (5). pp. 673-682. ISSN 1747-9541

It is advisable to refer to the publisher's version if you intend to cite from the work. http://dx.doi.org/10.1177/1747954116667105

For more information about UCLan's research in this area go to http://www.uclan.ac.uk/researchgroups/ and search for <name of research Group>.

For information about Research generally at UCLan please go to http://www.uclan.ac.uk/research/

All outputs in CLoK are protected by Intellectual Property Rights law, including Copyright law. Copyright, IPR and Moral Rights for the works on this site are retained by the individual authors and/or other copyright owners. Terms and conditions for use of this material are defined in the policies page. 


\title{
Preparation, structured deliberate practice and decision making in elite level football. The case study of Gary Neville (Manchester United FC and England).
}

\author{
David E Horrocks ${ }^{1,2}$, Jim McKenna ${ }^{3}$, Amy E Whitehead ${ }^{4}$, Paul J Taylor ${ }^{1}$, Andy M Morley ${ }^{1}$ and Ian Lawrence ${ }^{3}$ \\ ${ }^{1}$ School of Psychology, University of Central Lancashire, Preston, PR1 2HE, UK. Email, \\ dhorrocks2@uclan.ac.uk \\ ${ }^{2}$ International Centre for Football Research, UCFB Burnley and Wembley, UK \\ ${ }^{3}$ Institute of Sport, Physical Activity and Leisure, Leeds Beckett University, UK \\ ${ }^{4}$ School of Sports Studies, Leisure and Nutrition, Liverpool John Moores University, UK
}

Corresponding author:

David E Horrocks, International Centre for Football Research, UCFB Burnley and Wembley, UK.

Email: D.Horrocks@ucfb.com.

\begin{abstract}
Decision making in elite level sporting competition is often regarded as distinguishing success from failure. As an intricate brain-based process it is unlike other physical processes because it is invisible and is typically only evidenced after the event. This case study shows how an individual achieved great success in elite level professional football through consistent positive decision making on and off the field of play. Through prolonged interviewing, Gary Neville, a player from Manchester United Football Club, explored personal behaviours, the structure and activities of deliberate practice and his professional choices in match preparation. His career-long devotion to purposeful organised practice was focused on cognition, physical preparation, context-relative physical action and refined repetition to optimise his mental comfort while enhancing his match day performances. This approach was underpinned by diligent personal and collective organisation and by concerted action. Results provide an insight into the categorical nature of his deliberate practice, sport-specific information processing and match-based decision making. At the operational level his process was mediated by a complex mental representation of on-going and
\end{abstract}


anticipated game situations; these representations were continuously updated during each match. Allowing for the limitations of the design, implications are provided for developmental and educational coaching, match preparation, deliberate practice activity and improved use of performance analysis software packages in professional football.

\section{Key Words}

Decision making, preparation, deliberate practice, soccer, elite performance.

\section{Introduction}

While football is a physical invasion game of technique, strategy, tactics and skill, at the pinnacle of the professional game there is a growing awareness that perceptual cognitive skills account for a significant proportion of variance in performance between elite and nonelite athletes [1]. At the higher levels of football perceptual-cognitive skills are more likely to discriminate between performers than anthropometric and physiological skills [2]. The capacity to make correct decisions in the pressured environment of elite competition may all too often represent the distinction between success and failure. This 'chatter of a hundred billion nerve cells' [3] is the invisible phenomena that many professional athletes and coaches seek to understand and control.

In a recent interview article in performance magazine [4] elite level practitioner Tony Strudwick, current head of Sports Science for Manchester United and the England National team stated. "Working with elite athletes demands the highest level of attention towards preparation. We are now reaching a plateau in terms of physical fitness and there is a need for players who make quicker decisions in high pressure environments. I expect the next (scientific) developments to be in the areas of vision and cognition and the development of tools (to enhance vision and cognition) to take the game to another level".

Previously decision-making research (e.g., [5]) has primarily been conducted in laboratory environments using controlled tests. Such work has addressed advance cue utilization, pattern recognition, visual search behaviour and the use of situational probability as the basis for decision making [5]. This research typically focuses on whether players extract situational information for decision making from (i) contextual postural appearance, (ii) players' relative positions on the pitch, (iii) motion between groups of players and (iv) 
tactical information displayed by each players' positioning. Another direction in this research addresses whether specific players are regarded as more important than others and the extent and purpose of information that is drawn from teammates or opponents when making decisions.

Fundamentally, a central tenet of the decision-making process relies on pattern recall ability [6,7]. Pattern recall is important in high level cognitive functionality, providing a base for high level tactical decision making. There is also considerable evidence to suggest that expertise emerges as a result of adaptation to the unique demands of the specific sport [8] and ultimately such pattern recognition is a strong predictor of anticipation skill in sport [9]. Further, Ward et al., [10] found that superior performance predictions were best supported by a situation model-type mechanism as proposed by the long-term working memory (LTWM). For experts, LTWM is thought to provide a rich representation of the individual's world that involves encoding of multiple dynamic options. Functionally, LTWM allows immediate access to a range of finely filtered options for given situations [10].

Deliberate practice in sport [10] involves training that is specific, goal-oriented and purposeful. Deliberate practice has been defined as "individualised training activities especially designed by a coach or a teacher to improve specific aspects of an individual's performer through repetitive and successive refinement" [11] Ericsson \& Lehman, 1996, pp278]. In relation to elite performance, Ericsson, Krampe and Tesch-Tomer [12] proposed a theoretical framework that shows how experts use extended deliberate practice. However, a recent review of practice [13] concluded that practice as a sole variable was insufficient to explain differences in human performance. To date few studies e.g. [15, $16 \& 17]$ have identified the deliberate practice activities that most contribute to the development of perceptual cognitive expertise. Equally, the specific nature of deliberate practice activity in soccer (football) has yet to feature strongly in existing academic commentary [17].

A review of decision making literature in sport [5] also cites the need for research that profiles the practice history of exceptional athletes, particularly those demonstrating exceptional and consistently superior perceptual cognitive skills. Further, since so little attention has been paid to the analysis of these skills in elite players from the athlete's perspective, this underlines the need for qualitative approaches [18]. Eliciting in-depth qualitative accounts of the deliberate practice activities used by elite footballers, and how they influence cognition and decision making under pressure in games will add to the 
understanding of how these skills are developed and as such, contribute towards filling this academic void.

\section{Method}

The study adopted a single case design (SCD) based on a retrospective qualitative interview [19]. SCD's have been successfully applied to many research contexts including psychology, medicine, education, rehabilitation, social work, counselling and sport psychology [20]. Sport psychologists have been encouraged to use SCD's to develop evidence-based interventions for use in their applied work, while many already use single-case designs to explore intervention impact $[21,22]$. Indeed, to advance applied practice, research and theory, there are considerable advantages for sport psychologists to holistically embrace experimental, quasi-experimental, and non-experimental research methods.

The data capture and reduction process closely aligned with the requirements of Interpretative Phenomenological Analysis (IPA). Although this is an innovative approach to decision making research, it is based on the long standing work of Husserl, Heidegger, and MerleauPonty, this idiographic approach aims to provide in-depth insights into how individuals make sense of their life experiences [23]. The detail that this approach reveals stems from its close examination of experiences and the meaning ascribed as a "self-interpreting being" [24]. A further appeal of this approach was the room it furnishes for interviewees to provide finegrained accounts of the importance of their domain-specific practices. The project revolved around the questions of "What are their deliberate practice activities?", "How do professional soccer players engage in such activities within match preparation?" and "How does this ultimately affect cognition and decision making under pressure in games?" Where response were unclear, probes such as "Can you say more?" were used.

Initial contact with the player was made via a mutual friend. In the early stages, establishing a high level of trust was fundamental since part of the value of the work lies in naming the elite player in the published outputs it generates. Therefore, it was necessary to find common ground; the interviewer was a professional football coach and former youth player and this was emphasised in preliminary discussions about undertaking the study. The shared understanding that this fostered also provided reassurances about the maintenance of confidentiality where appropriate. It also helped to ensure that all contributions were interpreted accurately and as intended. 
Data capture focussed on an initial interview, followed by a clarification meeting conducted once the interview transcript had been analysed. A key feature of the approach was to encourage free speech, with no suggestion of judgement or interrogation. The interview and the follow-up meeting were extensive and in-depth, lasting over four hours in total. This was a demanding process for the interviewee and the interviewer, but was required to yield accurate insights into the lived experience and to provide an interpretive account of meanings [25].

The interview process was designed to generate self-revelation and to identify issues relevant to athletic preparation and match performance. The interview was intended to be an openended discussion, threaded with prompts to pursue emerging topics that were felt to be important. Throughout, to guide the interpretations that would follow, there was encouragement to describe the process on a visceral, emotional level around the idea of 'consistently superior performance' [11]. IPA interviews are required to be dynamic, allowing the researcher to take an active role in getting close to the participant's personal world [26]. The analysis that follows aims at 'sense-making'; this emerged through the efforts of the participant with the researcher and then between the researchers [27].

\section{Transcription}

Jeffersonian [28] transcription analysis was used to annotate the recordings. The Jeffersonian method is designed to capture not only what was said but the way in which it was said. Emotion, manner, tone, relativity and reasoning are all captured through this approach.

\section{Confirming the case for eliteness}

One definition of eliteness requires the collation of objective performance metrics, independent of cultural forces and subjective factors, and free from biases linked to reputation [29]. This synopsis of Gary Neville's achievements is presented to justify his selection as an elite footballer. Starting as a schoolboy aged 16, Neville went on to accumulate 602 professional appearances over two decades. His playing career became synonymous with unparalleled domestic, European and global success for his team, Manchester United Football Club (MUFC). During his playing career MUFC won more honours than any other professional English club. In total, Neville played in teams that won eight Premier League titles, three FA Cups, one European Champions League, an 
Intercontinental Cup, a FIFA Club World Cup, and one League Cup. Beyond his success with the MUFC team, Neville was first-choice right-back for his national team for more than ten years, making 85 appearances. Sir Alex Ferguson (MUFC Manager) described him as "the best English right-back of his generation" [30].

\section{Data analysis}

Data analysis consisted of a five step process [31]: Getting to know the data; Focusing the analysis; Categorising the information; Identifying patterns and connections within and between categories; Final interpretation. Any data considered to be rich/unique in content was also included in the final analysis. This type of data is likely to appear when a footballer is recalling individual games and scenarios to illustrate his behaviour to an 'outsider' researcher.

Emerging themes were then translated into a narrative account and explained further in the results section. Furthermore, an idiographic representation of cognitive processes of decision making, which are context specific to football, was produced (figure 2). This was based on the identified patterns and connections between categories and our prior knowledge of information processing theory [32].

\section{Results}

Findings are presented in two sections. In the first section football-specific, deliberate practice and the cycle of preparation is addressed. The second section includes an existential model of decision making 'in action', presented from a football-specific, information processing perspective. This model depicts the dynamic real-time cognitive functioning of an elite-level football brain. Focusing on internal psychological phenomena and on-going sport-specific analysis, the findings indicate an analytic ability that facilitates in-game decision making and engagement.

\section{Deliberate practice and preparation cycle}

Diligence, as represented by systematic and organised behaviour, underpinned the bulk of the structured deliberate practice behind Gary Neville's career and achievements. Figure 1 summarises the nature of this experience of elite level football and how he operated and achieved success within it. Figure 1 includes not only the behaviours of deliberate practice 
e.g. identify personal requirements and process focus but also the outcomes that were intended, e.g. winning mentality and social support.

In line with Jeffersonian transcript analysis quotes are presented using the following annotation key: (.) represents micro pause, a notable pause but of no significant length; (0.1) indicates a timed pause, long enough to show in transcription to express tone, emotion and visceral reality of prose; (0.2) indicates an extended timed pause.

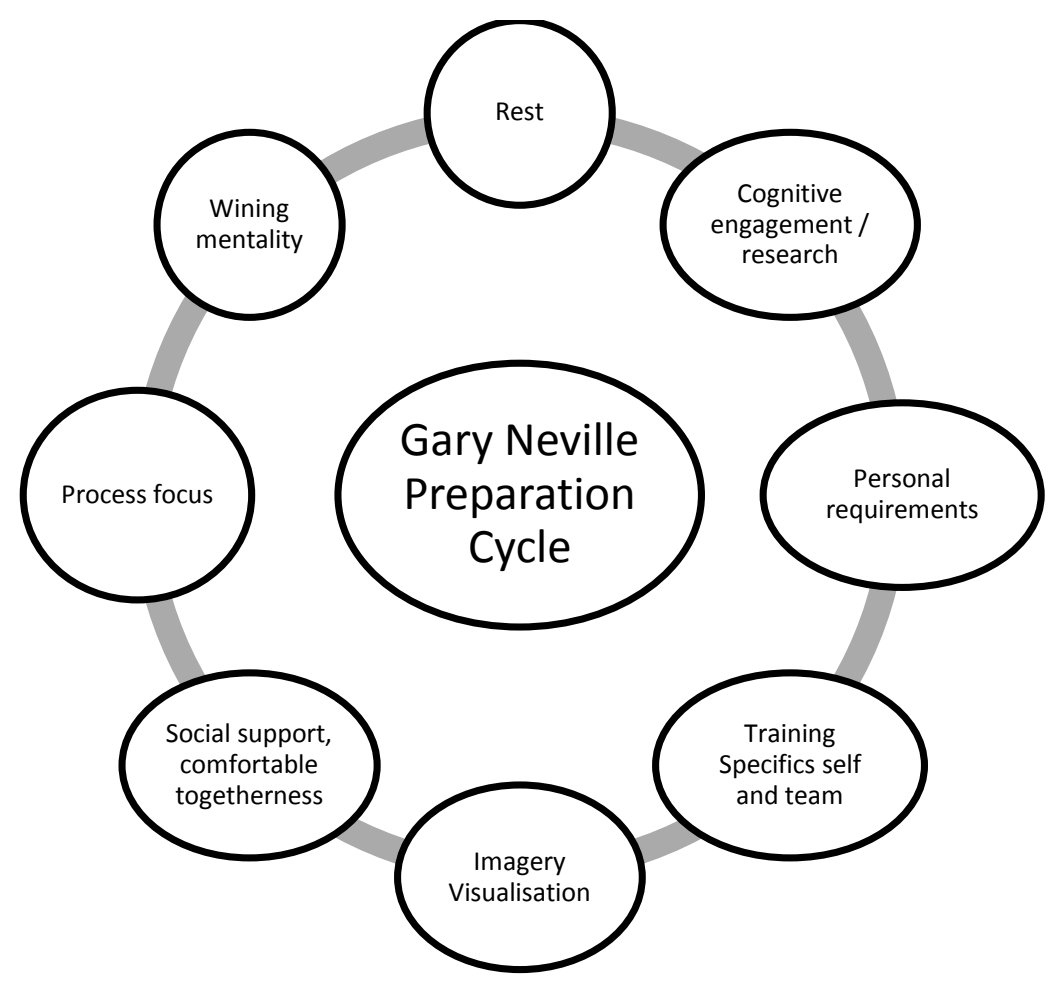

Figure 1. Preparation Cycle

In this first quote, GN articulates the importance of preparation at all stages of his career. The quote ends with his account of preparing for any match where he might be involved. This avoided the possibility of being unprepared through an unexpected call to play.

I would say preparation for a match has been the key to my career (.) If that's wrong (1) any element of it is wrong, I'm in trouble (.) my biggest lesson in life was preparation costing me (.) and (0.2) erm I never took that risk ever again (.) I mean it just didn't happen in my career (.) to this day (0.2) I just never took the risk that I was never going to be involved (0.2) just prepare as if you are playing (.) you just don't know what's going to happen. 
Drawing on Figure 1, an important initial deliberate action is to rest to clear his mind, to regulate his body and be in optimal condition for the workload that the next match will involve. While this represents the absence of physical effort its initiation was cognitively effortful.

yes (.) for me my routine and preparation for matches (.) that was critical to me (0.2) if I didn't do that I couldn't play (.) I was like I had a fixed routine and it was always (.) Tuesday morning (.) If we played Sunday (.) I would seriously have (.) in my mind (.) Monday off (.) night of the game you would come down a little bit (.) the day after the game recover (.) but not think too much about what's coming (.) you know obviously it's in your mind (.) but you wouldn't think (0.2) I wasn't in game mode

This was followed by cognitive engagement/personal research where he planned his approach for the forthcoming match and how to handle specific opponents or potential situations. This approach was supported by upholding a clear philosophy about personal preparation.

my game mode started Tuesday morning the minute you got to the airport before you travelled (.) and then literally the minute you got on that plane (.) every moment is thinking about that game for the Wednesday night and Thursday night for a Saturday game (.) you are just switching on (0.2) you're thinking (.) who am I playing against (.) right (.) what's he do (.) what do I need to do (.) do I need to watch a video of him (.) what do I need to practice in training... (0.3)

people have said to me, 'Did Overmars give you a problem?' (.) no he didn't (.) I could mark him quite simply (0.2) if Petit didn't get time on the ball to stand there (.) look up (.), Overmars is moving (.) look up again (.) look up again (.) and all of a sudden I'm knackered and he's gone (0.2) so for me (.) the key to stopping players is not sometimes just your direct opponent (0.2) its understanding who you need to work with you to stop it ().2) and they were just things that I worked out.

Once he established the evidence, he moved to think about what the evidence 'told' him to do. His focus was on his personal requirements in terms of tactics, technique, the physical aspect and/or any psychological or behavioural characteristics that may merit consideration. Importantly, he deployed a refined observational approach, seeking to understand how his opponents play and move, often before they get the ball. 
I would understand what I needed to do to defeat an opponent (.) to get the better of an opponent (.) I would ask for a video (0.2) I never liked watching picked or selected clips of teams by a coach. I have always liked to see half an hour (.) the first half an hour of a match (.) cause (0.2) I (.) er (.) for me (.) I (.) you can sort of see a player dribbling at somebody three times but I'm not really interested in that to be honest (0.2) that's probably the most obvious thing to look at (.) I'm looking at sort of erm (0.2) who gives him the ball (.) when do they give him the ball (.) what movements does he make to get on the ball (.) what weaknesses does he have (.) is he lazy (.) does he follow you back (.) If he was quicker than me I had to stop him in another way (.) I knew if had to be aggressive (.) I knew if I had to be nice (.) because some players you didn't want to wind up (0.2) they don't show you all these things in selected clips.

With the requirements established and confirmed, the plan was then converted into appropriate physical practice. These sessions involved simulations of what his opponents typically did in matches. These practices were persistently repeated until the challenge was clear; clarity came from identifying the scenarios - through markers and cues - that signalled how and when opponents' initiated their trademark moves, confidence then grew from successfully and repeatedly executing the appropriate skills and approaches that offset those opponents.

What do I need to do in this training session tonight? (.) Is he quick and jinky? (.) So I'll get somebody to run to me quick and jinky (.) Is he physical? (.) So I practice my heading (.) and that's the sort of (0.2) what I call more specific preparation (.) you just want repetition in your routine in terms of specific preparation (.) (0.2) it's just mimicking that thing that you know (.) that you're feeling as though the movements in your body are going to be replicated the day after (.) and then yes (.) I would say that (0.2) I'm convinced (.) repetition in training gives you the sort of comfort in the game that when it comes into that situation (.) you know you've done it before (0.2) I'm absolutely convinced (.) that's just fact (.) that's a given for me (0.2) repetition (.) and that feeling that I've been there before is an important feeling.

... I trained every day in my position (.) I played right back in training cause that's where I played (0.2) In small sided games, you should play in your position (.) warm up before a game (.) I pass in my position (0.2) and repetition of thought and imagery 
of what (.) you know (.) that's my outside pass (.) that's my inside pass (.) you know (.) you're in your area where you are gonna be.

Training was confirmed through visualisation and mental clarification of all these identified and practised behaviours. This enhanced psychological well-being (expressed by him as 'comfort'), providing personal belief in, and commitment to, the plan for match day.

I think that having a picture of the match before you play it (.) I think the first person that I heard say that was Terry Venables in '96 or '95 when he was England manager (.) he said that his job as a coach was to almost (0.2) in our minds have us going into the game having felt like we had already played it

All these activities were then affirmed and clarified through the peer and support network. This promoted further psychological wellbeing, generated a 'comfortable togetherness' and reaffirmed the worth and value of the processes that had already been deployed.

yeah (.) talking to people about the game (.) Scholesy (.) people in the changing room (.) you confide in people (.) Dad (.) brother (0.2) makes you feel comfortable (.) makes you feel more at ease because you get to know what they're thinking (0.2) you do get comfort I think out of discussion and sometimes clarity on things (0.1) sometimes they can give you a different view and you think (0.2) right okay

Work was then channelled into a solution-orientated, process-focussed match day state of mind with clear set of well-rehearsed actions.

It's vital to understand your individual opponent (.) the tactics of your opponents (0.2) and if you've got a manager and coaches who can explain to you how you can win that match before you've won (., before you had to go and play that match (0.2), then, to be honest with you, I think you are in a far better state of mind as a player

All actions were then re-emphasised when the team gathered. Focusing solely on this team, what they have to do and what it has done in the past all helped to foster belief, persistence, faith, relentlessness and an expectation that felt limitless. This left no room to envision anything other than positive outcomes.

you can't come into Man United's dressing room and talk about another team (.) We're Man United (0.2), talk about us (.) even though you respect the other team (.) you pay attention to the other team (.) you don't talk about them (0.2) I accept that 
what we are surrounded by is not normality (.) in terms of (.), you know, the level of mindset in the changing room (.) mentally unbelievable (.) I think (.) unbelievable (0.2) and that's my bias but an unbelievable mindset (.) never ever to give in (.) never say die (.) always just think you can win all the time and that shows in the performances (.) every game we come back in (.) every game we score in the last minute (0.2) that's come from the mindset of a manager who's just instilled it in a group of players.

Ultimately Gary Neville's deliberate practice and preparation (Findings 1) improved his mind set, which he believed facilitated better, and quicker, on-pitch decision making and reaction times. This type of preparation forged a perceived advantage for impending high pressure football matches; this may distinguish success from failure where the physical development of most competing players is at, or close to, optimum. This cognitive functionality may be what distinguishes elite level players from serial winning players and is an aspect of training that is increasingly required for success in modern day elite level football (Strudwick, cited in Hancock, 2014, [4]). It is important to acknowledge that some of these practices have also been widely identified in other elite environments such as music [35]; although this paper is football specific.

\section{Decision making processes}

This offers a preliminary operational model of the functional brain within a football game. Its originality derives from data from serially successful elite level football. The player perceived that his success was tied to the structured deliberate practice that he deployed in the preparation cycle (outlined in Findings 1). 


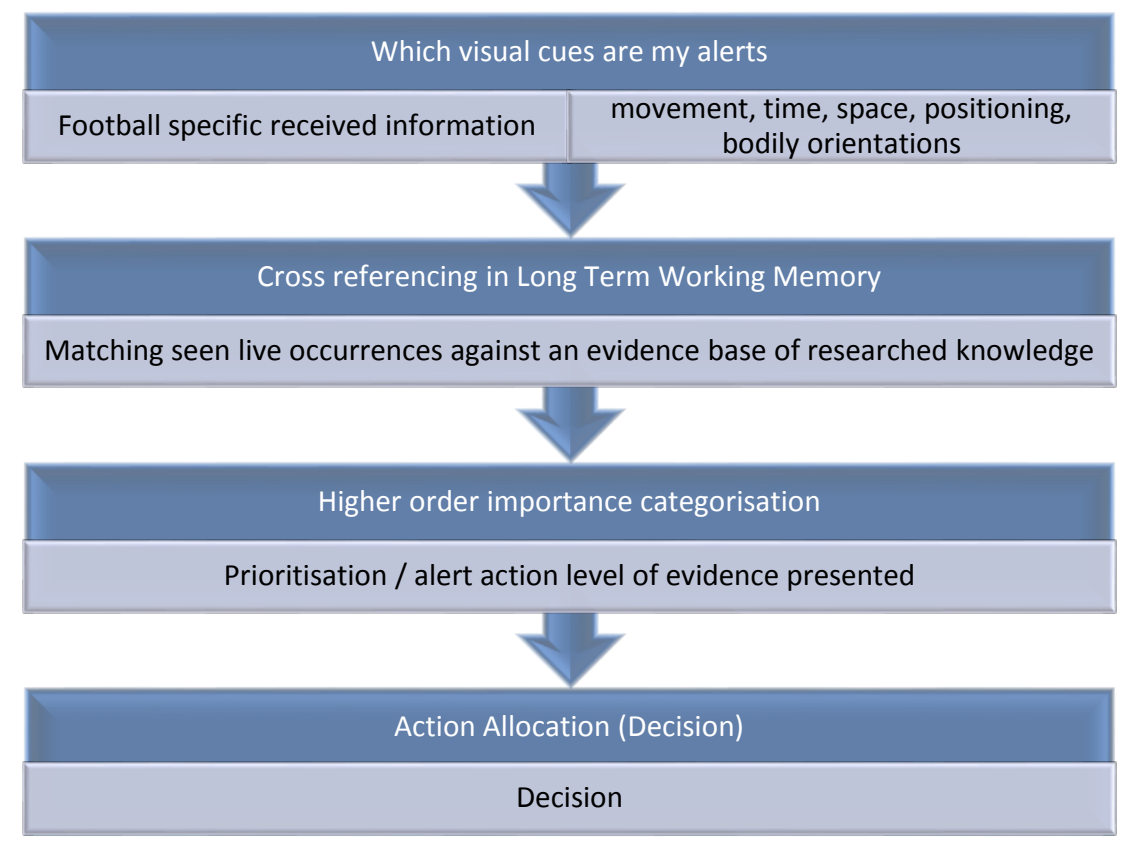

Figure 2. Idiographic of cognitive processes for decision making in football.

Information processing theory [32] proposes that humans process information rather than merely responding to stimuli. Information is taken in, encoded to give it meaning, compared to stored information (the players' football knowledge base), then evaluated and acted upon. Figure 2 represents the conscious decision making process during a football match, as it was depicted in the accounts of Gary Neville. This has four key points, all drawn from the idiographic account of the mental processing occurring during elite-level football matches.

1. Assessing received information

2. Cross referencing against mental images from experience (physically lived or educated through research)

3. Categorising the information's relevance / threat and allocating meaning

4. Allocating action / (The Decision)

Two further quotations detail the visceral experience of personal sense making; these illustrate decision making in action. They show (a) the prevalence of contingent thinking about options and (b) how other players were recruited to bring about desired tactical outcomes. The first quote describes how much information - especially that drawn from player positions, speeds, distances and players' identity - is assessed and then executed in a decision. 
... level of concentration I don't think should change through time (0.2) I think players speed changes (.) but then you change with that as well (.) that's a decision to make (.) that you give yourself more space if he's quicker than you (.) that's not a case that you have to concentrate more (0.2) the decisions change (.) the distances change (.) you're sort of (0.2) you know (.) you might (0.2) yes, your decision could change based upon the player that you are playing against.

This next example highlights that the information being assessed includes (i) ball technique, (ii) positioning of player groups and player relations, (iii) positioning and potential organisation of other Man Utd team members.

... for me (.) my problem with Overmars was Emannual Petit dropping it over my head (.02) it wasn't Overmars because no matter what that lad (0.2) if I dropped off too far he got it into his feet and he ran at me (.) if I got too tight to him (.) he'd spin and go in behind me (.) and it was easy for me to stop Overmars(0.2) I got Keaney to nail Petit and I got Becks to nail (0.2) rather than drop off and say protect me that way (.) get on top of them (.) stop them playing it forward (.) and I know I can get on top of him 'cause he can't get the ball (0.2) so that was the key for me.

This information, combined with stored knowledge, resulted in the player being able to make deliberate calculations and real time decisions. Working memory cross references with understanding acquired through the lived, learned and/or possibly simulated practices initiated within the Preparation Cycle (Figure 1.). The quality of this process is then demonstrated in the pressure of performance; the quality of this preparation may be the defining factor in distinguishing success from mediocrity or failure. This case study illustrates the inseparability of cognitive with physical functionality at the highest levels of professional football. With Neville paying so much attention to aligning these factors for each impending contest, the quality, volume and pattern of this deliberate practice may be what separates players - and teams - that may, otherwise, be considered equal.

\section{Discussion}

This study set out to discover the nature and activities of deliberate practice and the decision making process in elite level football. The study describes the match preparation activities as well as various cognitive processes employed during a match. Founded on case study data generated within an in-depth qualitative interview with an elite football player, the data 
represent a rare, first-hand account that is extensive in both quality and quantity. It also provides a detailed insight into the ways in which one elite athlete deployed deliberate practice to speed and refine his decisions in a game. These findings are important because the subtlety of these processes is often beyond the sensitivity of conventional research approaches. Equally, it is rare to find athletes who can do this in close detail and even rarer to find elite level athletes who are prepared to do it.

An eight stage cycle of preparation emerged. This facilitated the development of an idiographic model of Gary Neville's in-game decision making. We are presenting a lived experience, contextualised to football, which closely overlaps with existing information processing models. The outcomes also support the relevance of existing psychological theory (e.g., self reflection, social support, process focus, visualisation and mental toughness) for elite level soccer, while also offering new information regarding preparation for sustained success in elite level football that might inform practice structure and content. In turn, this may facilitate better coach education and individual preparation for prospective football players of all levels.

With regard to football-specific behaviours, Gary Neville deployed an extensive and refined approach to match preparation. Across many hours - both within and beyond physical training and practice - he carefully researched how his direct opponents played, both with and without the ball. This extensive process helped him to identify not only opponents' predictable patterns of movement but also the cues that signalled the start of these patterns; this enhanced his cognitive responsiveness and gave him vital extra time during matches. $\mathrm{He}$ then designed a self-oriented and solution-focussed action plan, committing to situationspecific physical practice. This built his psychological clarity and his view of how well he could expect to command the impending match.

The level of detailed preparation enhanced sport-specific working and long-term memory capacity for tactical situations. Such an approach to deliberate practice, it is argued, also increased his controlled and attentional focus. Equally, this activity promoted clarity of mind by reducing the likelihood that emotions and/or impulse would drive decision making [36]. The account also suggests that existing theory has captured much of what this elite level footballer can articulate about his decision making processes. The phrase 'what is most personal, is most universal' [29], drawn from counselling seems to apply to the relationship between elite level behaviour and current theory, regarding deliberate practice, information 
processing and decision making; this points to the value of the single case approach deployed intensively with appropriate and willing elite athletes. However, these findings need to be substantiated and confirmed in other elite level football players.

Equally, although this study is based on a single case design in football, there is consistency between Gary Neville's approach and established, formalised ways of working. For example, mental contrasting [30] is a positive, solution focussed, planned action, process oriented, activity for behavioural change where expectations of successful outcomes are high. Although he didn't know it, Neville's approach is highly resonant with the practice of mental contrasting. His account also offers extended and compelling evidence that such practice can be used in football to produce positive outcomes.

Based on the account from the current study, some of the critical components for good decision making capabilities appears to include (i) prior knowledge developed through careful observation, (ii) accurate identification of an appropriate action sequence, (iii) experience of deploying solutions in practice simulations (iv) feeling reassured that the 'needs analysis' was correct and that the required responses had been integrated into the playing repertoire. The player's preparatory cycle was refined, confirmed and supplemented by integrating information provided by coaching staff and the complimentary use of analysis technologies. All this work extended his personal commitment to developing a wide, subtle understanding of opponents' in-match habits and routines.

This text provides numerous examples to suggests that Neville's analytical approach, which includes a personalised expertise in using match recordings, is highly distinctive, although the scale of this distinctiveness needs to be confirmed. While this distinctiveness inevitably reflects methodological influences, it still sets him apart in terms of consciously focusing on developing finely tuned anticipatory skills, reactive readiness and clear situation-specific intentions. He is also distinctive for being able to articulate his approach so closely.

Clearly then, for this player, information about opponents and elements of match-based 'pattern recognition' are key components in his approach to match preparation. Although powerful analysis software is readily available in professional football, few players have learned to optimise the capabilities of this software, meaning that its optimal use in supporting elite level football performance has yet to be achieved. The evidence provided by the current study shows that Gary Neville used video technology in innovative and facilitative ways. 
His diligence generated an advantageous position regarding potential incidents; this not only built his confidence for oncoming matches but also directly affected his role and performance within the team during such matches. This behavioural nuance was key in securing athletic advantage over opponents. The evidence presented proposes the potential of careful and considered use of video technology in preparing for performance in professional football; for Gary Neville this was mostly self-initiated. Importantly, when video is well used, it enhances the likelihood of players being fully engaged in a highly functional form of deliberate practice. That practice needs to be context relevant, accurate and significant to the player.

Yet, this practice also needs to move with the times. Manchester United Head of Sport Science Tony Strudwick recently stated "The manner in which we communicate data to the athletes is key. Generation Y athletes are technologically savvy, so we're always looking at ways in which we can develop how we educate and stimulate them" [4]. In the way of every virtual circle, linking playing success to previous cycles of preparation will reinforce commitment to the nuances of this approach. Without this, practice risks losing its deliberateness by becoming non-specific, abstract and irrelevant. Neville's account provides ample lines for enhancing match planning, both for coaches and players.

\section{LIMITATIONS AND FUTURE DIRECTIONS}

While the study provides a unique insight into expert performance - as understood by the expert - it provides isolated, idiographic evidence. Reliance on a single case obviously imposes considerable boundaries on the relevance of our proposed model; all qualitative accounts are limited by the perceptual range of the account maker. This makes it difficult to uphold the principles of qualitative research while also addressing whole theoretical frameworks around decision making. Equally, it will be important to compare this preparation cycle to those of other athletes both within and beyond soccer. It is also important to acknowledge that although this paper suggests a direct link between the preparation cycle and decision making, the way in which qualitative data is revealed makes it difficult to verify cause and effect. Subsequent studies based on longitudinal comparative analysis should be considered.

These limitations caution against assuming the relevance of the model to individual sports and/or to sports where (sub) groups of athletes work together more - and possibly better than in soccer. However, since Gary Neville has detailed his life across a long and sustained career and realised serial winning, his account clearly offers intensive generalizability; this 
represents the insider's detailed view of what contributed to this success throughout his journey. While the study provides rich data, established through an intensive process; not all expert athletes will be willing or able to do this to the required level. Therefore, and allowing for this being an unusual 'case' based on a demanding approach, replication will be important to establish the credibility of these outcomes.

Further, subsequent studies, based on larger samples and longitudinal designs would establish extensive generalizability of issues detailed within this particular piece of work. They would also allow comparisons with other sports and/or performance domains, establish which of the behaviours are imperative elements of deliberate practice - versus those which merely coincide - and which have emerged in sequences of refinement. Given it's prominence in the current study; it may also be pertinent to conduct further studies on how video analysis is optimised by coaches, players and the interactions between these particular groups of people.

\section{Conclusion}

Existing academic research has little to say about how serial winners at the elite level achieve their success. This account, based on a serially successful player in professional football, underlines the cycle of preparation he developed, deployed and continued to refine. This cycle represents this players' unwitting realisation of 'deliberate practice'. Importantly the study shows the sequence running into a game, and highlights the nuanced ways in which video analysis was used and reused to fully grasp, and then physically practice, the demands that players in the impending match might impose on him. The study offers a template for coaches, players and performance technology providers to improve current practice to increase the likelihood of more successful outcomes. Gary Neville understood that preparation and due diligence were of paramount importance as the speed of the game increased and the number of incidents rose. His approach to preparation showed football as imposing multi-dimensional demands. These extensive demands are often inseparable in-themoment of play, involving psychological and physical components that responded to his carefully constructed, experientially-based, version of deliberate practice.

\section{REFERENCES}

[1] Reilly T, Williams, AM, Nevill, A and Franks, A. A multidisciplinary approach to talent identification in soccer. Journal of Sports Sciences 2000; 18: 695-702. 
[2] Williams, AM and Reilly, TP. Talent identification and development in soccer. Journal of Sport Sciences 2000; 18: 657-667.

[3] Marsh H. Do no harm. London: Orion Ltd, 2014.

[4] Hancock D. Future of sport. Performance 201; 03: 54-56.

[5] Williams, AM and Ward, P. Anticipations and decision making exploring new horizons. In: Tenenbaum G and Eklund RC (eds) Handbook of Sport Psychology. $3^{\text {rd }}$ ed. Hoboken, New Jersey: Wiley \& Sons, 2007.

[6] de Groot A.D. Thought and choice in chess. The Hague, The Netherlands: Mouton, 1978.

[7] Simon HA and Chase WG. Skill in chess. American Scientist 1973; 61: 394-403.

[8] Williams AM and Ericsson KA. Perceptual-cognitive expertise in sport: some considerations when applying the expert performance approach. Human Movement Science 2005; 24: 283-307.

[9] Williams AM and Davids K. Declarative knowledge in sport: a biproduct of experience or a characteristic of expertise? Journal of Sport and Exercise Psychology 1995; 7(3): 259-275.

[10] Ward P, Hodges NJ, Starkes LJ and Mark A. The road to excellence: deliberate practice and the development of expertise. High Ability Studies 2007; 18(2): 119-153.

[11] Ericsson KA and Lehmann AC. Expert and exceptional performance: evidence of maximal adaptations to task constraints. Annual Review of Psychology 1996; 47: 273-305.

[12] Ericsson KA, Krampe RTH and Tesch-Ro"mer C. The role of deliberate practice in the acquisition of expert performance. Psychological Review 1993; 100: 363-406.

[13] Ericsson KA. The development of elite performance and deliberate practice: an update from the perspective of the expert-performance approach. In: Starkes J and Ericsson KA. (eds.), Expert Performance in Sport: Recent Advances in Research on Sport Expertise. Champaign, IL: Human Kinetics, 2003, pp. 49-81.

[14] Hambrick DZ, Oswald FL, Altmann EM, et al. Deliberate practice: is that all it takes to become an expert? Intelligence 2014; 45: 34-45. 
[15] Baker J, Cote J and Abernethy B. Learning from the experts: practice activities of expert decision makers in sport. Research Quarterly for Exercise and Sport 2003a: 74(3): 342-347.

[16] Baker J, Cote J and Abernethy B. Sport-specific practice and the development of expert decision making in team ball sports. Journal of Applied Sport Psychology 2003b: 15: 12-25.

[17] Ward P, Hodges NJ, Williams AM and Starkes JL. Deliberate practice and expert performance: defining the path to excellence. In: Williams AM and Hodges N (eds.) Skill acquisition in sport: research, theory and practice. London: Routledge, 2004, pp. 231-258.

[18] Cotterill S. Pre-performance routines in sport: current understanding and future directions. International Review of Sport and Exercise Psychology 2010; 3(2): 132-153.

[19] Côté J, Ericsson K and Law M. Tracing the development of athletes using retrospective interview methods: a proposed interview and validation procedure for reported information. Journal of Applied Sport Psychology 2005; 117: 1-20.

[20] Kazdin AE. Single-case research designs: methods for clinical and applied settings. $2^{\text {nd }}$ ed. New York: Oxford University Press, 2011.

[21] Barker JB, McCarthy PJ and Jones MV and Moran AP. Single-case research in sport and exercise psychology. London: Routledge, 2011.

[22] Hemmings B and Holder T. Applied sports psychology: a case based approach. Chichester, Wiley, 2009.

23] Reid K, Flowers $P$ and Larkin M. Exploring lived experience: an introduction to interpretative phenomenological analysis. The Psychologist 2005; 18: 20-23.

[24] Smith JA and Eatough, V. Interpretative phenomenological analysis. In: Breakwell GM, Hammond S, Fife-Schaw C and Smith JA (eds) Research methods in psychology. 3rd ed. London: Sage, 2006.

[25] Denzin NK and Lincoln YS. Introduction: the discipline and practice of qualitative research. In: Denzin, N.K. and Lincoln, Y.S (eds) Handbook of qualitative research. 2nd ed. London: Sage Publications, 2000.

[26] Smith JA. Beyond the divide between cognition and discourse: using interpretative phenomenological analysis in health psychology. Psychology and Health 1996; 11: 261-271. 
[27] Hoffman RR, Trafton G and Roebber P. Minding the weather: how expert forecasters think. Cambridge MA: MIT Press, 2006.

[28] Jefferson G. Glossary of transcript symbols with an introduction. In: Lerner GH (eds) Conversation analysis: studies from the first generation. Amsterdam: John Benjamins, 2004, pp. 13-31.

[29] Ericsson KA, Nandagopal K and Roring R W. An expert-performance approach to the study of giftedness. In: Shavinina L (eds) International handbook of giftedness. Berlin, Germany: Springer Science. Business Media, 2009, pp. 129-153.

[30] Ferguson A. Managing my life. Hodder \& Stoughton. London: 2011.

[31] Taylor Powell E and Renner M. Analysing qualitative data. University of Wisconsin: 2003 .

[32] Welford AT. Single-channel operation in the brain. Acta Psychologica 1967; 27: 5-22. 